\title{
Side effect profile of Jadelle implant in Nigerian women during the first 12 months of usage
}

\author{
Emmanuel C. Inyang-Etoh*, Anietimfon S. Akpan
}

Department of Obstetrics and Gynaecology, University of Uyo, Akwa Ibom State, Nigeria

Received: 26 February 2016

Accepted: 23 March 2016

\section{*Correspondence:}

Dr. Emmanuel C. Inyang-Etoh,

E-mail: emmacol2000@yahoo.com

Copyright: (c) the author(s), publisher and licensee Medip Academy. This is an open-access article distributed under the terms of the Creative Commons Attribution Non-Commercial License, which permits unrestricted non-commercial use, distribution, and reproduction in any medium, provided the original work is properly cited.

\section{ABSTRACT}

Background: Most of the reasons for discontinuation of Jadelle implants by clients are related to the progestogenic side effects, which are dependent on the plasma levels of the hormone. The plasma level of levonorgestrel from Jadelle implant is about $100 \mu \mathrm{g}$ in the first month of insertion, but declines sharply in the first 12 months of usage to stabilize at $30 \mu \mathrm{g}$ per day from 24 months of usage. This study was designed to assess the side effect profile of Jadelle implant in users during the first 12 months of usage in a view to assessing its acceptability to the clients.

Methods: Data sheet was designed to obtain demographic and clinical parameters of clients and prevailing side effects were surveyed longitudinally over the first 12 months of usage.

Results: There was no request for discontinuation of the method and no accidental pregnancy occurred during the period of the study. There was significant disruption of the menstrual pattern of clients over time with $31.1 \%$ developing irregular uterine bleeding from 6months of usage, whereas $16.6 \%$ of clients became amenorrheic from the 12 month of usage. $(p=0.000)$ Changes in blood pressure and body weight of clients were not significant during the 12 month period of the survey. Non menstrual side effects of Jadelle implants, which included headache, breast tenderness, dizziness among clients were noted at 6months of usage but became less prevalent by the $12 \mathrm{month}$ of usage.

Conclusions: Jadelle implant proved to be highly effective, safe and acceptable to Nigerian clients during the study period, even though the implant had significant impact on their menstrual pattern.

Keywords: Jadelle implant, Side effects, Menstrual pattern, Clients, Nigeria

\section{INTRODUCTION}

Jadelle is a sub-dermal implant which provides safe, convenient, highly efficacious and long term method of fertility regulation to married and other sexually active women. ${ }^{1-3}$ Jadelle is a contraceptive system that consists of two implantable $43 \mathrm{~mm}$ rods, each consisting of a drugreleasing core encased in thin-walled silicone rubber tubing sealed at both ends. The core of each rod consists of $50 \%$ by weight of levonorgestrel, $75 \mathrm{mg}$ and $50 \%$ of elastomer. The calculated mean daily in vivo release rate of levonorgestrel provided by the implants is about $100 \mu \mathrm{g} / \mathrm{day}$ at the first month, followed by a decline to about $40 \mu \mathrm{g} /$ day at 12 months, and to about $30 \mu \mathrm{g} /$ day at 24months, with a stabilization thereafter at about $30 \mu \mathrm{g} /$ day. $^{4,5}$

Due to the difficulty associated with insertion and removal of Norplant, the six-rod pioneer sub-dermal implants, and the inevitable abandonment of the method in many countries of the world, the need for biodegradable implants or at least implants with fewer rods became imperative. ${ }^{5}$ This development resulted in the invention of Jadelle, a two-rod implant providing fertility regulation for 5years, and Implanon, a single rod implant which regulates fertility for 3years. ${ }^{5,6}$ Following development of Jadelle, it was subjected to multicentre trials beginning from 1990, and the trials enrolled 1393 
rod users in seven countries. These trials provided assuring data on blood levels, safety and efficacy of Jadelle. ${ }^{7,8}$ The use of Jadelle was subsequently approved by several countries across Europe, America and parts of Asia. ${ }^{8}$

Women tend to try different contraceptive methods during their reproductive life, ostensibly in search of an ideal method. This trend may be influenced by the woman's age, marital status, health status and lifestyle. Jadelle seems to be favoured and accepted by a large proportion of women in both developed and developing countries. $^{9,10,11}$ The majority of women who choose Jadelle do so because of their dissatisfaction with other methods of contraception, and a large proportion of the implants users find it convenient and highly effective in the prevention of unwanted pregnancies. ${ }^{12-14}$ Many women discontinue Jadelle however when they decide to become pregnant, although the commonest reason for early discontinuation is irregular prolonged uterine bleeding. ${ }^{15,16}$ Implants are not associated with long term health risks, and may be used safely in women with contraindications to estrogen-containing contraceptives. The effect it has on the cervical mucus by thickening it may be beneficial as it protects against ascending upper genital tract infections. ${ }^{17,18}$

Notwithstanding the high efficacy and other benefits of implants, the method requires a minor surgical procedure for both insertion and removal, and these are dependent on the health provider. In addition, they can be visible and palpable at the site of insertion and they do not protect against sexually transmitted infections. ${ }^{19}$ Similar to other progestin-only contraceptives, Jadelle causes alterations in the normal pattern of menstrual bleeding; this may be in form of irregular menstrual bleeding, prolonged menstrual bleeding or cessation of menstruation. ${ }^{8}$ Non menstrual side effects of implants, which may occur infrequently include headache, acne, mastalgia, weight changes, and mood changes. ${ }^{15,17}$

Most serious side effects of implants are progestindependent and they are prevalent during the first 12 months of usage; such side effects could compel affected women to discontinue the method, therefore this study was designed to assess the side effect profile of Jadelle implant in Nigerian women during the first 12 months of usage in order to appraise their acceptance of the method.

\section{METHODS}

\section{Study design and study area}

This was a longitudinal descriptive study of clients who used Jadelle implants for the first 12 months at the Family Planning Unit of the University of Uyo Teaching Hospital, Uyo, Nigeria over a 2 year period, from $1^{\text {st }}$ of January, 2013 to the $31^{\text {st }}$ December, 2014. The University of Uyo Teaching hospital is the only tertiary level health care facility in Akwa Ibom State, which is located in the south-east health zone of Nigeria. The state has a population of 3.9 million people according to the Nigerian census conducted in 2006 and projected to 4.8million people by $2014 .^{20,21}$ Akwa Ibom state is one of the 36 states of the federal republic of Nigeria, and it has one federal university teaching hospital, 3 academic institutional medical centres, 16 general hospitals and 125 private clinics. $^{22}$

Uyo, the capital of Akwa Ibom State is inhabited largely by the Ibibios, the Annangs and the Oros, who are the indigenous tribes of the state living together with some other Nigerian tribes like the Igbos, Efiks, Yorubas, Hausas and Fulanis. ${ }^{20}$ The people of the state are predominantly government employed civil servants, and other persons indulging in peasant farming, petty trading and small scale businesses. ${ }^{20}$

\section{Data collection and analysis}

Approval was obtained from the University of Uyo Teaching Hospital Ethical Committee before commencement of the study. The nurses working in the Family Planning Unit of the hospital who were six in number were intimated on the nature and purpose of the study and trained on how to administer the data sheets to clients who opted for Jadelle implants during the period of the study. They were instructed on the need to follow up the clients at 6 monthly intervals for the first one year of usage while the investigators regularly visited the unit for guidance and supervision. Clients were counseled on the purpose of the study and informed that participation in the study was voluntary.

The data sheet were designed to allow for the clients' demographic data, parity, contraceptive method last used and menstrual pattern on presentation prior to Jadelle use to be obtained. The client's blood pressure and body weight were also measured on presentation. At 6months and 12 months of usage, the prevailing menstrual pattern, non-menstrual side effects, the body weight and blood pressure were reassessed by the same set of nurses using standard techniques and recorded in the data sheet.

Data generated from the study were coded and entered into the software of the Statistical Package for Social Sciences (SPSS), Version 17 Inc. Chicago, Ilinois, USA. The data are presented in numerical, percentages and simple proportion, and descriptive and inferential statistics were performed for continuous variables. Longitudinal comparisons were done at 6 months and 12 months for clinical parameters and side effects among clients and differences were considered significant at Pvalues of less than 0.05 .

\section{RESULTS}

During the 2 year period of the study, there were 2432 clients using different methods of contraception in the family planning unit of the University of Uyo Teaching hospital. Clients who used dermal implants during the period were 196 in number, with 158 of them using 
Jadelle, giving a method utilization rate of $6.5 \%$. Only 132 of the Jadelle users volunteered and participated to the end of the study and therefore constitute the study population.

Table 1: Demographic and obstetric parameters of Jadelle implant users.

\begin{tabular}{|c|c|c|}
\hline Age (years) & No. & Percentage (\%) \\
\hline$<25$ & 8 & 6.1 \\
\hline $25-29$ & 11 & 8.3 \\
\hline $30-34$ & 20 & 15.2 \\
\hline $35-39$ & 52 & 39.4 \\
\hline$>40$ & 41 & 31.0 \\
\hline \multicolumn{3}{|l|}{ Marital status } \\
\hline Single & 16 & 12.2 \\
\hline Married & 91 & 68.9 \\
\hline Widowed & 25 & 18.9 \\
\hline \multicolumn{3}{|l|}{ Educational level } \\
\hline None & 9 & 6.8 \\
\hline Primary & 19 & 14.4 \\
\hline Secondary & 43 & 32.6 \\
\hline Post-secondary & 61 & 46.2 \\
\hline \multicolumn{3}{|l|}{ Occupation } \\
\hline Unemployed & 15 & 11.3 \\
\hline Unskilled labour & 27 & 20.5 \\
\hline Semiskilled labour & 59 & 44.7 \\
\hline Skilled work & 31 & 23.5 \\
\hline \multicolumn{3}{|l|}{ Parity } \\
\hline Para 0 & 5 & 3.8 \\
\hline Para 1 & 12 & 9.1 \\
\hline Para 2 & 22 & 16.7 \\
\hline Para 3 & 40 & 30.3 \\
\hline$>$ Para 4 & 53 & 40.1 \\
\hline \multicolumn{3}{|c|}{ Contraceptive method last discontinued } \\
\hline None & 10 & 7.6 \\
\hline Male condom & 14 & 10.6 \\
\hline ®COCP & 21 & 15.9 \\
\hline ®DMPA & 30 & 22.8 \\
\hline Implanon & 25 & 18.9 \\
\hline ®IUCD & 32 & 24.2 \\
\hline
\end{tabular}

®COCP - combined oral contraceptive pill; DMPA - Depot medroxyprogesterone acetate; IUCD - intrauterine contraceptive device; Mean age of clients $=36.11$ years +1.53 .

Table 1 shows the demographic and obstetric parameters of Jadelle users. The majority of Jadelle users belonged to the 35-39year age group with a mean age of 36years+1.53. A vast majority $(68.9 \%)$ of Jadelle users were married multiparous women $(40.1 \%)$ who had attained post-secondary $(46.2 \%)$ level of education. A significant proportion of them discontinued from intrauterine contraceptive device $(24.2 \%)$ and depomedroxyprogesterone acetate $(22.8 \%)$ to use Jadelle.
The menstrual pattern, changes in blood pressure and alterations in body weight of clients during the 12 months period under review is shown in Table 2. There was a statistically significant alteration in the menstrual pattern of clients to irregular uterine bleeding $(31.1 \%)$ from the 6 month of usage, whereas amenorrhea in $16.6 \%$ of clients only occurred from the 12 months usage. Changes in blood pressure and body weight of clients were not significant during the period of the survey.

Table 3 shows the non-menstrual side effects of Jadelle among users during the 12 months longitudinal survey. Non menstrual side effects were noted in clients from the 6 months of usage, but there was a drop in the proportion of clients who had these side effects by the 12 month of the survey, although, the difference was not statistically significant.

\section{DISCUSSION}

The invention and improvements on subdermal implants as a method of fertility regulation in sexually active women the world over has made Jadelle a contraceptive method of choice. This is occasioned by its high efficacy, safety profile, reversible long term protection and widespread acceptability by women of all races, notwithstanding, the few tolerable side effects. The proportion of clients who used Jadelle implants in the study centre during the study period was $6.5 \%$, lower than a prevalence of $16.8 \%$ obtained 3years earlier in the same unit. ${ }^{3}$ The reason for the drop in utilization rate of Jadelle implant is not clear, although it is to be noted that the earlier study covered a period of 4years. During the 12 months longitudinal survey of clients, there was no request for discontinuation of the implant and no accidental pregnancy occurred, in agreement with findings from several other studies. ${ }^{3,4,23,24}$

The majority (40.1\%) of Jadelle users in the study population were multiparous married $(68.9 \%)$ women with a mean age of $36.11 \pm 1.53$, and $46.2 \%$ of them had attained post-secondary level of education. These clients' demographic parameters were comparable to those of Jadelle users in Port Harcourt, Nigeria where the majority of the clients in that series were multiparous women with a mean age of 33.1years. Notwithstanding, most $(89.33 \%)$ of the clients in the Port Harcourt series were married with $69.33 \%$ having attained post-secondary level of education. ${ }^{23}$ In contrast, a study in Thailand had clients with a younger mean age of 29.07years, and most of them were educated only to the secondary level. ${ }^{4}$

During the 12 months longitudinal survey, a large proportion of clients had their menstrual pattern disrupted with $30.3 \%$ developing irregular uterine bleeding by the 6 month of usage and $16.6 \%$ becoming amenorrheic from the 12 month of usage. $(p=0.000)$ This trend is noted in all studies where the side effects of Jadelle implants were assessed. $^{4,23-26}$ 
Table 2: Effects of Jadelle implant on clinical parameters of clients during the first 12 months of usage.

\begin{tabular}{|c|c|c|c|c|}
\hline \multirow{2}{*}{ Characteristics } & \multicolumn{3}{|c|}{ Duration on treatment } & \multirow[t]{2}{*}{ Test statistics and values } \\
\hline & 0 months & 6 months & 12 months & \\
\hline \multicolumn{5}{|l|}{ Menstrual pattern } \\
\hline Regular & $110(83.3)$ & $83(62.9)$ & $69(52.3)$ & \multirow{3}{*}{$\begin{array}{l}X 2=37.00 \\
D F=4 \\
P=0.000\end{array}$} \\
\hline Irregular & $20(15.2)$ & $40(30.3)$ & $41(31.1)$ & \\
\hline Amenorrhoea & $2(1.5)$ & $9(6.8)$ & $22(16.6)$ & \\
\hline \multicolumn{5}{|l|}{ Blood Pressure } \\
\hline$<=100 / 60$ & $51(38.6)$ & $45(34.1)$ & $47(35.6)$ & \multirow{5}{*}{$\begin{array}{l}X 2=4.958 \\
D F=8 \\
P=0.762\end{array}$} \\
\hline $101-120 / 61-70$ & $34(25.8)$ & $35(26.5)$ & $38(28.8)$ & \\
\hline $111-120 / 71-80$ & $26(19.7)$ & $28(21.2)$ & $18(13.6)$ & \\
\hline $130-140 / 81-90$ & $19(14.4)$ & $20(15.2)$ & $26(19.6)$ & \\
\hline$>140 / 90$ & $2(1.5)$ & $4(3.0)$ & $3(2.3)$ & \\
\hline \multicolumn{5}{|l|}{ Body weight (Kg) } \\
\hline$<60$ & $15(11.4)$ & $13(9.9)$ & $10(7.6)$ & \multirow{5}{*}{$\begin{array}{l}X 2=2.033 \\
D F=8 \\
P=0.980\end{array}$} \\
\hline $60.0-69.9$ & $34(25.7)$ & $32(24.2)$ & $34(25.7)$ & \\
\hline $70.0-79.9$ & $48(36.4)$ & $48(36.4)$ & $45(34.1)$ & \\
\hline $80.0-89.9$ & $19(14.4)$ & $21(15.9)$ & $23(17.4)$ & \\
\hline$>90.0$ & $16(12.1)$ & $18(13.6)$ & $20(15.2)$ & \\
\hline
\end{tabular}

Table 3: Non menstrual side effects of Jadelle implant in clients during the first 12 months of usage.

\begin{tabular}{|c|c|c|c|}
\hline \multirow{2}{*}{ Characteristics } & \multicolumn{2}{|c|}{ Duration on treatment } & \multirow{2}{*}{ Statistical tests and values } \\
\hline & 6 months & 12 months & \\
\hline Headache & & & $X 2=1.536$ \\
\hline Yes & $16(12.1)$ & $10(7.6)$ & $\mathrm{df}=1$ \\
\hline No & $116(87.9)$ & $122(92.4)$ & $\mathrm{P}=0.302 *$ \\
\hline Breast tenderness & & & $\mathrm{X} 2=1.321$ \\
\hline Yes & $5(3.8)$ & $2(1.5)$ & $\mathrm{df}=1$ \\
\hline No & $127(96.2)$ & $130(98.5)$ & $\mathrm{P}=0.447 *$ \\
\hline Dizziness & & & $\mathrm{X} 2=1.035$ \\
\hline Yes & $6(4.5)$ & $3(3.3)$ & $\mathrm{df}=1$ \\
\hline No & $126(95.5)$ & $129(97.7)$ & $\mathrm{P}=0.500^{*}$ \\
\hline Acne & & & $\mathrm{X} 2=3.816$ \\
\hline Yes & $13(9.8)$ & $5(3.8)$ & $\mathrm{df}=1$ \\
\hline No & $119(90.2)$ & $127(96.2)$ & $\mathrm{P}=0.085^{*}$ \\
\hline Alopecia & & & $\mathrm{X} 2=0.349$ \\
\hline Yes & $7(5.3)$ & $5(3.8)$ & $\mathrm{df}=1$ \\
\hline No & $125(94.7)$ & $127(96.2)$ & $\mathrm{P}=0.769 *$ \\
\hline Reduced Libido & & & $\mathrm{X} 2=1.321$ \\
\hline Yes & $5(3.8)$ & $2(1.5)$ & $\mathrm{df}=1$ \\
\hline No & $127(96.2)$ & $130(98.5)$ & $\mathrm{P}=0.447^{*}$ \\
\hline Mood changes & & & $X 2=0.516$ \\
\hline Yes & $5(3.8)$ & $3(3.3)$ & $\mathrm{df}=1$ \\
\hline No & $127(96.2)$ & $129(97.7)$ & $\mathrm{P}=0.722 *$ \\
\hline
\end{tabular}

In a study in Thailand where Jadelle users with irregular uterine bleeding were randomized into celecoxib drug and placebo groups, those on celecoxib had improved irregular uterine bleeding with higher levels of satisfaction than clients on placebo $(\mathrm{p}<0.001) .^{27}$ This intervention should probably be considered in order to ameliorate the impact of Jadelle on clients' menstrual function. Similar to results from other studies where the side effects of Jadelle were assessed, our study failed to show any significant changes in blood pressure and body weight during the 12 month longitudinal survey of clients. ${ }^{4,23}$ However, studies in Asia showed significant weight gain in some clients warranting request for removal of the implant, while a study in Pakistan found significant increase in mean body weight of clients by the end of 2 years of usage. ${ }^{23,28}$ 
There were a few non-menstrual side effects in Jadelle users in this study noted at 6months of usage, although the proportion of clients who had these side effects by the 12 month of survey decreased, in agreement with similar studies elsewhere in the world. ${ }^{4,25,26}$ Conversely, a different study found in addition more serious side effects like upper limb neuropathies, nervousness, visual disturbances, arthropathies, and non-clinical depression. ${ }^{26}$ Such symptoms seem to be duration- dependent as they were noted in the $4^{\text {th }}$ and $5^{\text {th }}$ years of usage in that series.

In conclusion, Jadelle implant proved highly effective, safe and acceptable to Nigerian clients during the period of the study. While it significantly disrupted the menstrual pattern of clients, none of them opted for discontinuation of the method during the study period. The impact of Jadelle on the blood pressure, body weight and non-menstrual side effects of clients were not remarkable.

\section{ACKNOWLEDGEMENTS}

We wish to acknowledge with a heart of gratitude the nurses in the Family Planning Unit of the University of Uyo Teaching Hospital who served as research assistants by interviewing clients, taking measurements and entering each client's information into the data sheet designed for the study.

\section{Funding: No funding sources}

Conflict of interest: None declared

Ethical approval: The study was approved by the Institutional Ethics Committee of the University of Uyo Teaching Hospital before commencement of the study

\section{REFERENCES}

1. Croxatto HB. Progestin implants for female contraception. Contraception. 2002;65(1):21-7.

2. Population Council. Norplant levonorgestrel implants. A summary of scientific data. New York: Population Council 1990.

3. Abasiattai AM, Utuk NM and Inyang-Etoh EC. Subdermal contraceptive implants: Profile of acceptors in a tertiary hospital in southern Nigeria. International Journal of Gynecology, Obstetrics and Neonatal care. 2014;1:9-13.

4. Laphikanont W, Taneepanichskul S. Effects of Jadelle used in Thai women aged between 2024years in King Chulalongkorn Memorial Hospital. J Med Assoc Thai. 2006;89(6):761-6.

5. Ramchandran D. Upadhyay UD. Implants: The next generation population reports series, No. 7 Baltimore, INFO Project John Hopkins Bloomberg School of Public Health, October 2007.

6. Meirik O. Implantable contraceptives for women. Hum Reprod Update Contraception. 2003;9(1):4959.

7. Coutinho E, de Sonza J, Athayde C, Barbosa K, Alvarez F, Brache V, et al. Multicentre clinical trial on the efficacy and acceptability of a a single contraception implant of nomegestrel acetate. Uniplant. Contraception. 1996;53:121-5.

8. Affandi B. An integrated analysis of vaginal bleeding patterns in clinical trials of Implanon. Contraception. 1998;58(6 Suppl):99S-107S.

9. Basnayake S, Thapa S, Balogh SA. Evaluation of safety, efficacy and acceptability of norplant implants in Sri Lanka. Stud Fam Plann. 1988;19(1):39-47.

10. Salah M, Ahmed AG, Abo-Eloyoun M, Shaaban MM. Five year experience with Norplant implants in Assiut, Egypt. Contraception. 1987;35(6):543-50.

11. Ortayli N. Users perspectives on implantable contraceptives for women. Contraception. 2002;65(1):107-11.

12. Sivin I, Robertson DN, Stern J. Croxatto HB, Diaz S, Coutinho E, et al. Norplant: Reversible implant contraception. Stud Fam Plann. 1980;11:227-35.

13. Darney PD. Subdermal progestin implant contraception. Curr Opin Obstet Gynecol. 1997;3:470-6.

14. Darney PD, Atkinson E, Tanner S, Macpherson S, Hellerstein S, Alvarado A, et al. Acceptance and perceptions of Norplant among users in San Francisco, USA. Stud Fam Plann. 1990;21:152-60.

15. Fraser IS, Tiitinen A, Affandi B, Brache V, Croxatto HB, Diaz S, et al. Norplant consensus statement and background review. Contraception. 1998;57(1):1-9.

16. Diaz J, Fandes A, Olmos P, Diaz M. Bleeding complaints during the first year of Norplant implants use and their impact on removal rate. Contraception. 1996;53(2):91-5.

17. Meirik O, Farley TM, Sivin I. Safety and efficacy of levonorgestrel implant, intrauterine device and sterilization. Obstet Gynecol. 2001;97(4):539-47.

18. Trussell J, Leveque JA, Koenig JD, London R, Borden S, Henneberry $\mathrm{J}$, et al. The economic value of contraception. A comparison of 15 methods. Am J. Public health. 1995;85(4):494-503.

19. Darney PD, Callegari LS, Swift A, Atkinson ES, Robert AM. Condom practices of urban teens using norplant contraceptives implants, oral contraceptives and condoms for contraception. Am $\mathbf{J}$ Obstet Gynecol. 1999;180(4):929-37.

20. National Population Commission (NPC) Nigeria. National Demographic and Health Survey (NDHS) National Population Commission, Abuja. 2014.

21. National Population Commission (NPC) Nigeria. Population of Akwa Ibom State. Final Report of the Nigerian Census 2006.

22. Akwa Ibom State Ministry of Health (AKSMOH). Number of health facilities and health personnel in the state. Updated Statistics of the Akwa Ibom State Ministry of Health for the year 2014.

23. Enyindah CE, Kasso T. Jadelle subdermal Implants. Preliminary experience in a teaching hospital in the Niger Delta region of Nigeria. Niger $J$ Med. 2011;20(2):270-4. 
24. Thamkhantho M, Jivasak-Apimas S, Angsuwathana S, Chiravacharadej G, Intawong J. One year assessment of women receiving subdermal contraceptive implant at Siriraj Family planning Clinic. J Med Assoc Thai. 2008;91(6):775-80.

25. Ladipo OA, Akinso SA. Contraceptive implants. Afr J Reprod Health. 2005;9(1):16-23.

26. Sivin I. Risk and benefits, advantages and disadvantages of levonorgestrel- releasing contraceptive implants. Drug Saf. 2003;26(5):30335.

27. Buasang K, Taneepanichskul S. Efficacy of celecoxib on controlling irregular uterine bleeding secondary to jadelle use. J Med Assoc Thai. 2009;92(3):301-7.

28. Sivin I, Campodonico I, Kiriwat O, Holma P, Diaz S, Wan L. et al. The performance of levonorgestrel and norplant contraceptive implants: a 5 year randomized study. Human Reprod. 1998;13(12):3371-8.

Cite this article as: Inyang-Etoh EC, Akpan AS. Side effect profile of Jadelle implant in Nigerian women during the first 12 months of usage. Int J Reprod Contracept Obstet Gynecol 2016;5:14616. 